\title{
Sequential treatment from mandibulectomy to reconstruction on mandibular oral cancer - Case review I: mandibular ramus and angle lesion of primary intraosseous squamous cell carcinoma
}

\author{
Won-Bum Lee, Dae-Seok Hwang, Uk-Kyu Kim \\ Department of Oral and Maxillofacial Surgery, School of Dentistry, Pusan National University, Yangsan, Korea
}

\begin{abstract}
J Korean Assoc Oral Maxillofac Surg 2021;47:120-127)
Primary intraosseous squamous cell carcinoma (PIOSCC) is very rare type of squamous cell carcinoma (SCC) that occurs within the jaw and arises from remnants of odontogenic epithelium with no connection to the oral mucosa. This study reports two cases of PIOSCC of the mandible. Reported in this article are two cases of PIOSCC of the mandible that were treated with resection and reconstruction using a fibular free flap. The first case was a 36-year-old male patient who complained of right mandibular pain. Computed tomography (CT) and panoramic radiograph revealed a large radiolucency in the mandibular ramus area. At first, an odontogenic keratocyst was tentatively diagnosed, and an excision procedure was carried out at another clinic. A final biopsy after cyst enucleation revealed well-differentiated SCC, so we proceeded with segmental mandibulectomy and reconstruction using a fibular free flap. The second case was a 48-year-old male patient with left mandibular pain. CT and panoramic radiograph revealed irregular radiolucency in the mandibular angle area near tooth \#38. At first, osteomyelitis was tentatively diagnosed, and a curettage was carried out. A later biopsy revealed well-differentiated SCC, so segmental mandibulectomy and reconstruction with a fibular free flap were secondarily performed. Our two cases have had no recurrence. The facial appearance of both patients is satisfactory, and the neo-mandibular body created using a fibular bone transfer displays adequate bony volume.
\end{abstract}

Key words: Oral squamous cell carcinoma, Mandibular reconstruction

[paper submitted 2020. 9. 28 / revised 2020. 11. 18 / accepted 2020. 11. 20]

\section{Introduction}

Primary intraosseous squamous cell carcinoma (PIOSCC) is a type of squamous cell carcinoma (SCC) that arises within the jaw, has no initial connection with the oral mucosa, and presumably develops from residues of the odontogenic epithelium or from an odontogenic cyst or tumor ${ }^{1-6}$. According to the World Health Organization (WHO) classification published in 2005, the term "PIOSCC" is intended to replace old terms, and its subtypes include solid type and that derived from odontogenic cyst ${ }^{1,7}$. There are three subcategories of

\section{Uk-Kyu Kim \\ Department of Oral and Maxillofacial Surgery, Pusan National University Dental Hospital, 20 Geumo-ro, Mulgeum-eup, Yangsan 50612, Korea \\ TEL: +82-55-360-5112 \\ E-mail:kuksjs@pusan.ac.kr \\ ORCID: https://orcid.org/0000-0003-1251-7843}

(a) This is an open-access article distributed under the terms of the Creative Commons Attribution Non-Commercial License (http://creativecommons.org/ licenses/by-nc/4.0/), which permits unrestricted non-commercial use, distribution, and reproduction in any medium, provided the original work is properly cited.

Copyright (C) 2021 The Korean Association of Oral and Maxillofacial Surgeons. All rights reserved.
PIOSCC:

1. A solid neoplasm that invades the bone marrow space and induces osseous resorption

2. SCC that arises from the lining of an odontogenic cystic lesion, a category that is subdivided into carcinomas arising in odontogenic keratocysts and carcinomas arising in other odontogenic cysts

3. SCC associated with other epithelial odontogenic tumors.

This study presents the features of two cases of PIOSCC and a review of the literature.

\section{Case Presentation}

\section{Case 1}

A 36-year-old male patient visited Pusan National University Dental Hospital in July 2013, for pain in the right mandibular region from the mandibular body to the mandibular ramus. Computed tomography (CT) and panoramic radiography revealed a large mandibular radiolucency.(Fig. 1) 
Odontogenic keratocyst was tentatively diagnosed, and excision with extraction of teeth \#47 and \#48 was carried out at another clinic. The specimen biopsy from the first surgery indicated the presence of well-differentiated SCC (cT4N0M0).

The patient underwent additional magnetic resonance imaging (MRI), enhanced CT, and positron emission tomography-CT (PET-CT). The MRI and CT revealed a 3.9-cm restricted diffusion in the right mandibular body. No enhancing lymph nodes with diffusion restriction were found. The maximum standardized uptake value (SUVmax) was 7.8 on PET-CT, which showed no metastatic lymph nodes.(Fig. 2)

Supraomohyoid neck dissection (SOHND) was performed at our hospital on the right side along with wide excision and segmental mandibulectomy. This patient had an intraoral
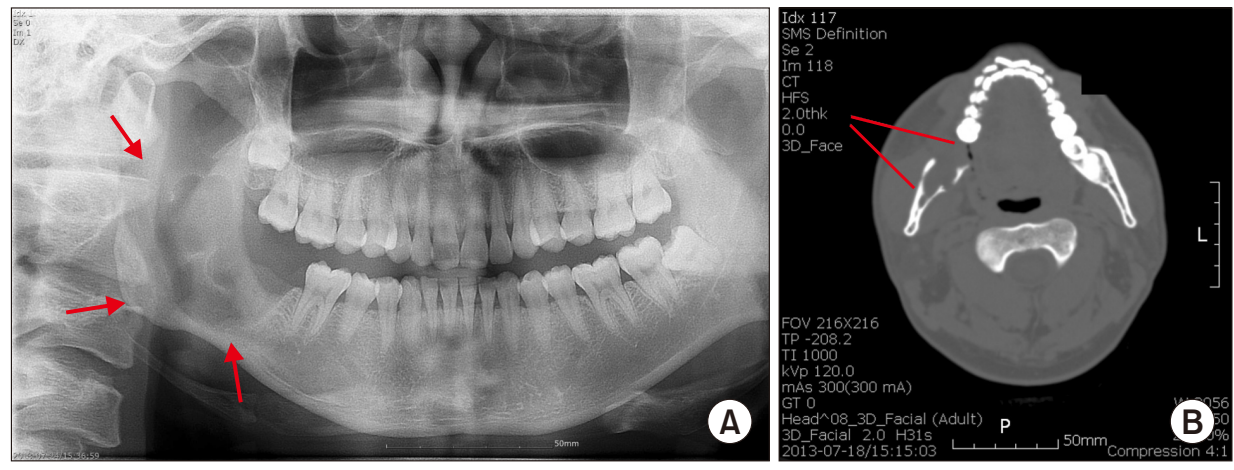

Fig. 1. Panoramic radiograph (A) and computed tomography (B) showed an ill-defined radiolucent lesion on right mandible (arrows).

Won-Bum Lee et al: Sequential treatment from mandibulectomy to reconstruction on mandibular oral cancer-Case review I: mandibular ramus and angle lesion of primary intraosseous squamous cell carcinoma. J Korean Assoc Oral Maxillofac Surg 2021
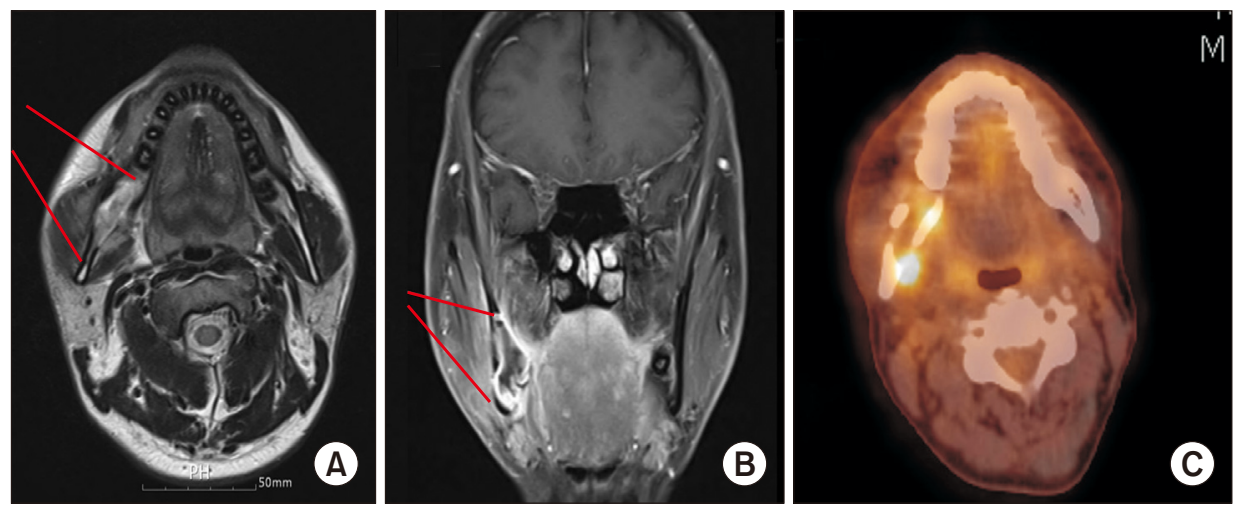

Fig. 2. Magnetic resonance imaging (MRI) (A, B) and positron emission tomography-computed tomography (PET-CT) (C) images. A, B. The lesion showed $3.9 \mathrm{~cm}$ restricted diffusion on right mandibular body in MRI. C. The maximum standardized uptake value was 7.8 in PET-CT.

Won-Bum Lee et al: Sequential treatment from mandibulectomy to reconstruction on mandibular oral cancer-Case review I: mandibular ramus and angle lesion of primary intraosseous squamous cell carcinoma. J Korean Assoc Oral Maxillofac Surg 2021
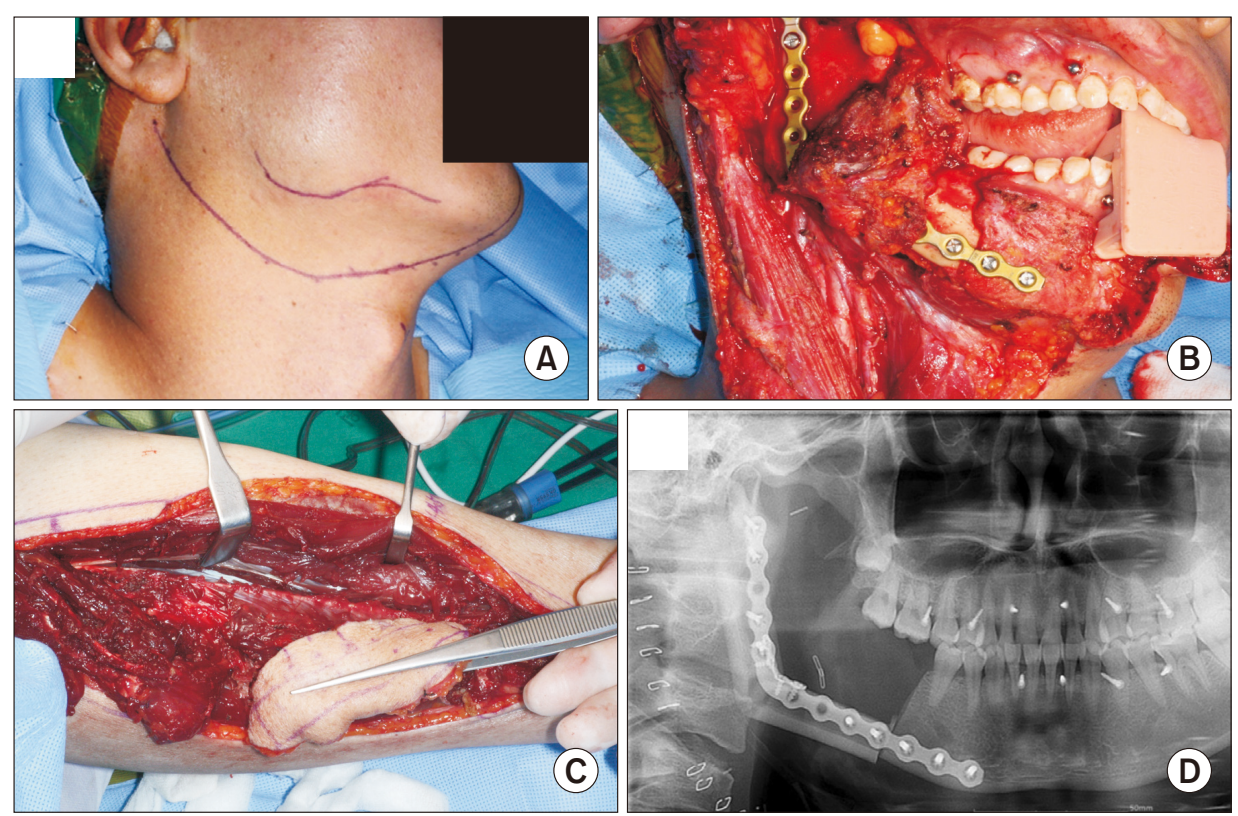

Fig. 3. A, B. Lesion on extraoral and intraoral site. C, D. Clinical (C) and radiographic (D) view of fibular free flap reconstruction.

Won-Bum Lee et al: Sequential treatment from mandibulectomy to reconstruction on mandibular oral cancer-Case review I: mandibular ramus and angle lesion of primary intraosseous squamous cell carcinoma. J Korean Assoc Oral Maxillofac Surg 2021 
defect and ipsilateral neck vessels, so a contralateral fibular free flap was chosen to cover the intraoral defect and resected mandible $\operatorname{areas}^{8}$. Mandibular ramus reconstruction with a two-piece fibular free flap was carried out after mandibular resection.(Fig. 3) The biopsy indicated the presence of a solid tumor of the PIOSCC type (pT4aN0M0).(Fig. 4) At first, the multilocular radiolucency seen on radiographs was considered to be SCC arising from an odontogenic cyst. However, pathologic findings revealed no cystic lining in the lesion. The mandibular resection defect was successfully anastomosed with a fibular free flap.(Fig. 5) The patient was not given postoperative radiotherapy or chemotherapy due to the presence of a clear surgical margin and the absence of neck node metastasis. Seven years after mandibular resection and reconstruction, no recurrence has been observed.

\section{Case 2}

A 48-year-old male patient visited Pusan National University Dental Hospital in April 2020, with pain in the left mandibular region and paresthesia of the left lower lip. A radiolucent lesion was visible near the root of his wisdom tooth (\#38) at the mandibular angle. Osteomyelitis was tentatively diagnosed, and curettage along with extraction of tooth \#38 was carried out.(Fig. 6) The biopsy suggested a PIOSCC (cT4aN1M0) lesion (SCC arising from the lining of an odontogenic cyst).

The patient underwent additional MRI, enhanced CT, and PET-CT. MRI and CT revealed a $1.8-\mathrm{cm}$ restricted diffusion on the left mandibular body that extended to the lateral aspect of the left medial pterygoid muscle and the medial aspect of the left masseter muscle. An enhancing lymph node with diffusion restriction in the left neck at the IIa level also was identified. The SUVmax was 6.3 on PET-CT, which revealed a level-IIa metastatic lymph node.(Fig. 7)

SOHND was performed on the patient's left side. Wide excision and segmental mandibulectomy were carried out. A Mandibular Reconstruction Angled Plate (Stryker, Kalamazoo, MI, USA) was prepared preoperatively using a rapid prototype model and was used as the reconstruction plate after being cut according to the bone resection site.(Fig. 8) This patient also had an intraoral defect and ipsilateral neck vessels, so a contralateral fibular free flap was chosen ${ }^{8}$. After resection, mandibular reconstruction was carried out using a fibular free flap.(Fig. 9) The biopsy result indicated the pres-

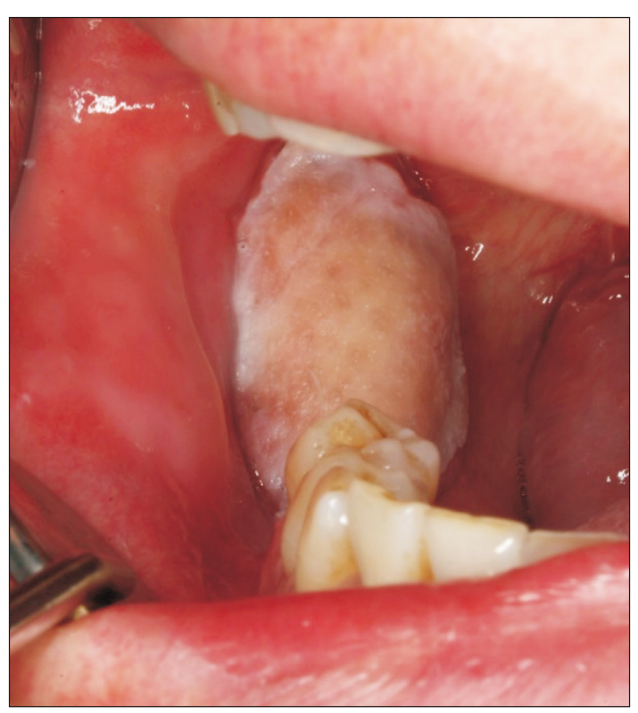

Fig. 5. The patient's intraoral view after 2 months postoperatively. Won-Bum Lee et al: Sequential treatment from mandibulectomy to reconstruction on mandibular oral cancer - Case review I: mandibular ramus and angle lesion of primary intraosseous squamous cell carcinoma. J Korean Assoc Oral Maxillofac Surg 2021
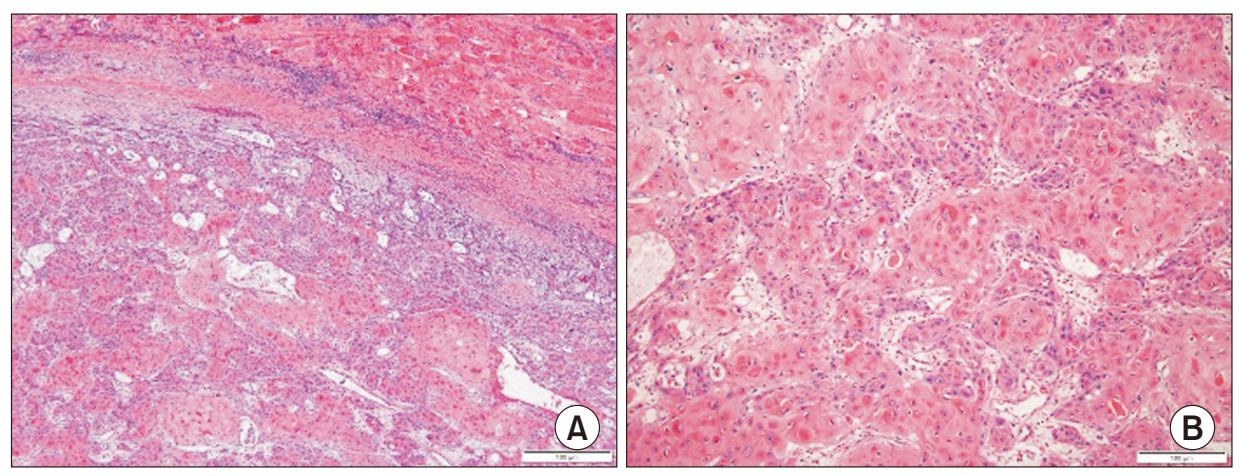

Fig. 4. Histological findings of Case 1 (H\&E staining). A. Hole view of the lesion ( $\times 20)$. B. Magnification view ( $\times 100)$ of the part of the solid tumor type primary intraosseous squamous cell carcinoma (PIOSCC) which demonstrate the general feature of a squamous cell carcinoma.

Won-Bum Lee et al: Sequential treatment from mandibulectomy to reconstruction on mandibular oral cancer-Case review I: mandibular ramus and angle lesion of primary intraosseous squamous cell carcinoma. J Korean Assoc Oral Maxillofac Surg 2021 

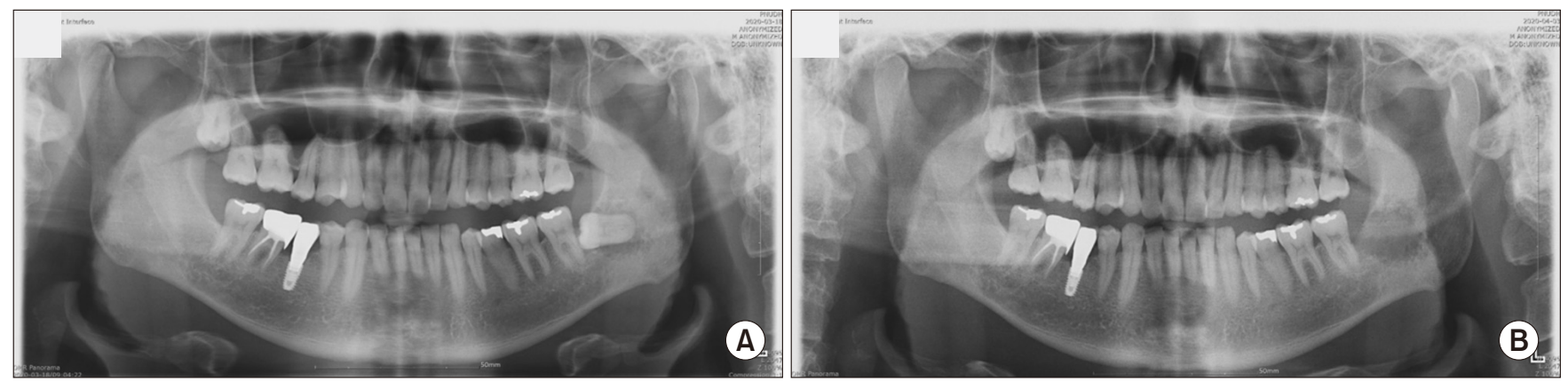

Fig. 6. A. A panoramic radiograph showed an ill-defined radiolucent lesion and impacted wisdom tooth on left mandible. At first, the osteomyelitis was tentative diagnosed and curettage with extraction of \#38 was done. B. A panoramic view after curettage and extraction of \#38.

Won-Bum Lee et al: Sequential treatment from mandibulectomy to reconstruction on mandibular oral cancer - Case review I: mandibular ramus and angle lesion of primary intraosseous squamous cell carcinoma. J Korean Assoc Oral Maxillofac Surg 2021
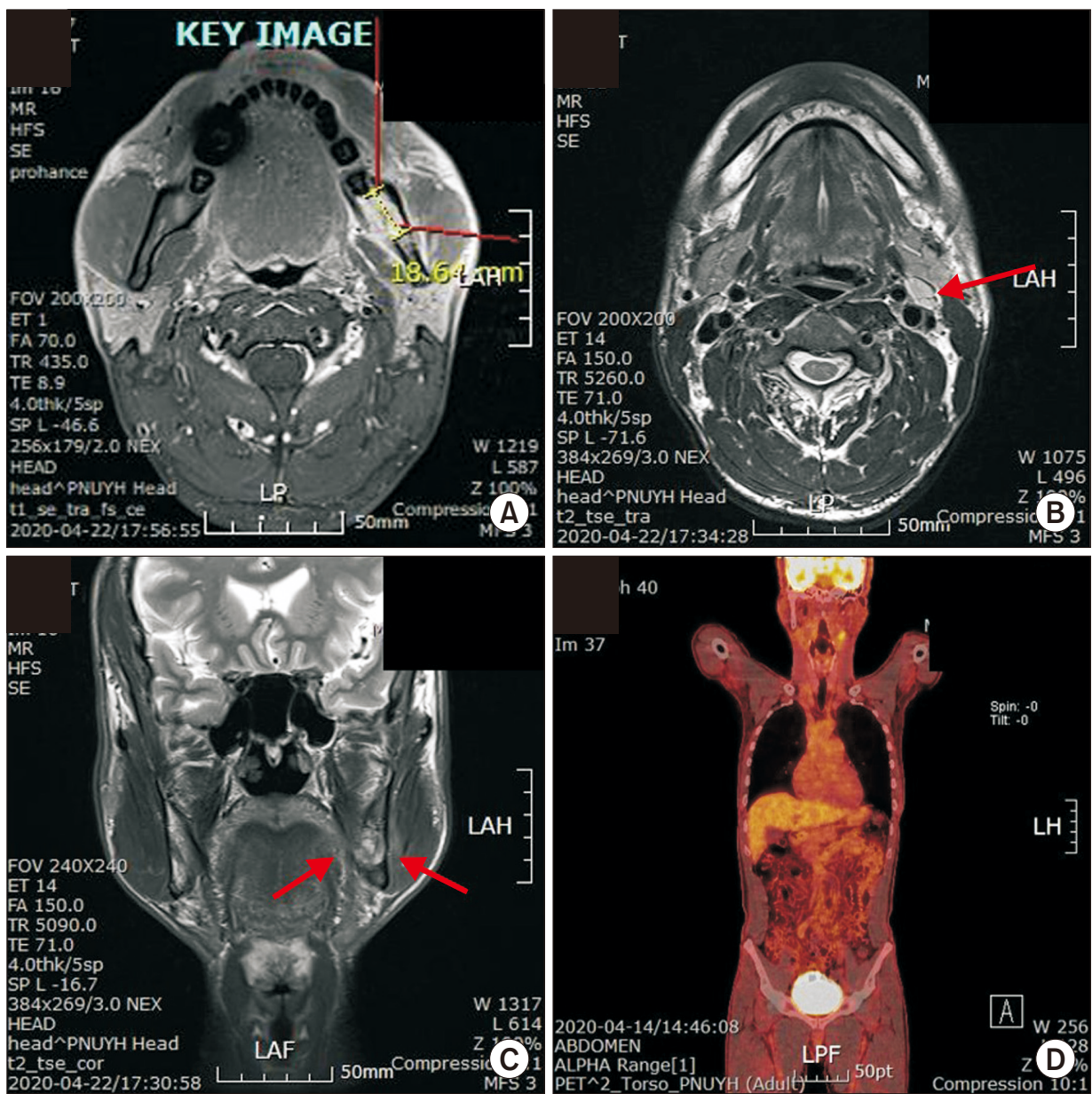

Fig. 7. Magnetic resonance imaging (AC) and positron emission tomographycomputed tomography (PET-CT) (D) images. A. The lesion showed $1.8 \mathrm{~cm}$ restricted diffusion on left mandibular body. B. An enhancing lymph node with diffusion restriction in left neck level lla was found (arrow). C. The lesion extended to the lateral aspect of the left medial pterygoid muscle and the medial aspect of the left masseter muscle (arrows). D. Level Ila metatstatic lymph node also detected in PET-CT.

Won-Bum Lee et al: Sequential treatment from mandibulectomy to reconstruction on mandibular oral cancer - Case review I: mandibular ramus and angle lesion of primary intraosseous squamous cell carcinoma. J Korean Assoc Oral Maxillofac Surg 2021

ence of well-differentiated SCC arising from the lining of an odontogenic cyst (pT4aN1M0).(Fig. 10) The mandibular resection defect was successfully anastomosed with the fibular free flap.(Fig. 11) The patient received 30 cycles of postoperative radiotherapy (60 Gy) and chemotherapy using cisplatin to prevent tumor recurrence. Four months after mandibular resection and reconstruction, there was no inflammation or other complications, and no recurrence has occurred. 

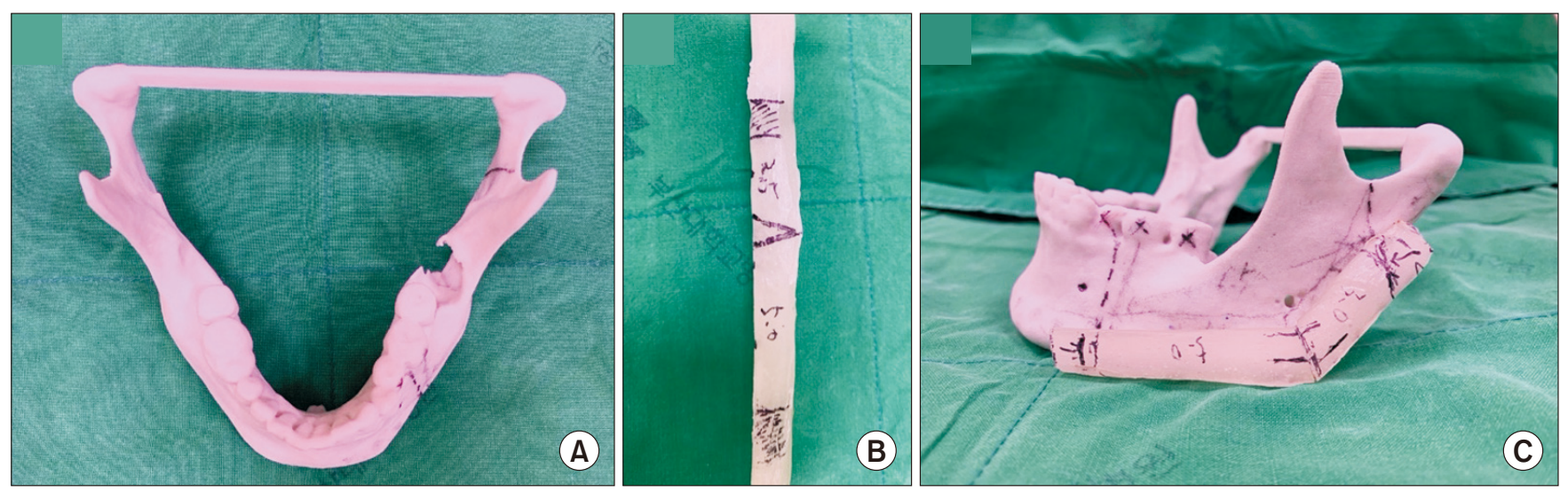

Fig. 8. Rapid prototype (RP) model. A. RP model of mandible. B. Fibular resin model. C. Required bone graft design with resin block. Won-Bum Lee et al: Sequential treatment from mandibulectomy to reconstruction on mandibular oral cancer-Case review I: mandibular ramus and angle lesion of primary intraosseous squamous cell carcinoma. J Korean Assoc Oral Maxillofac Surg 2021
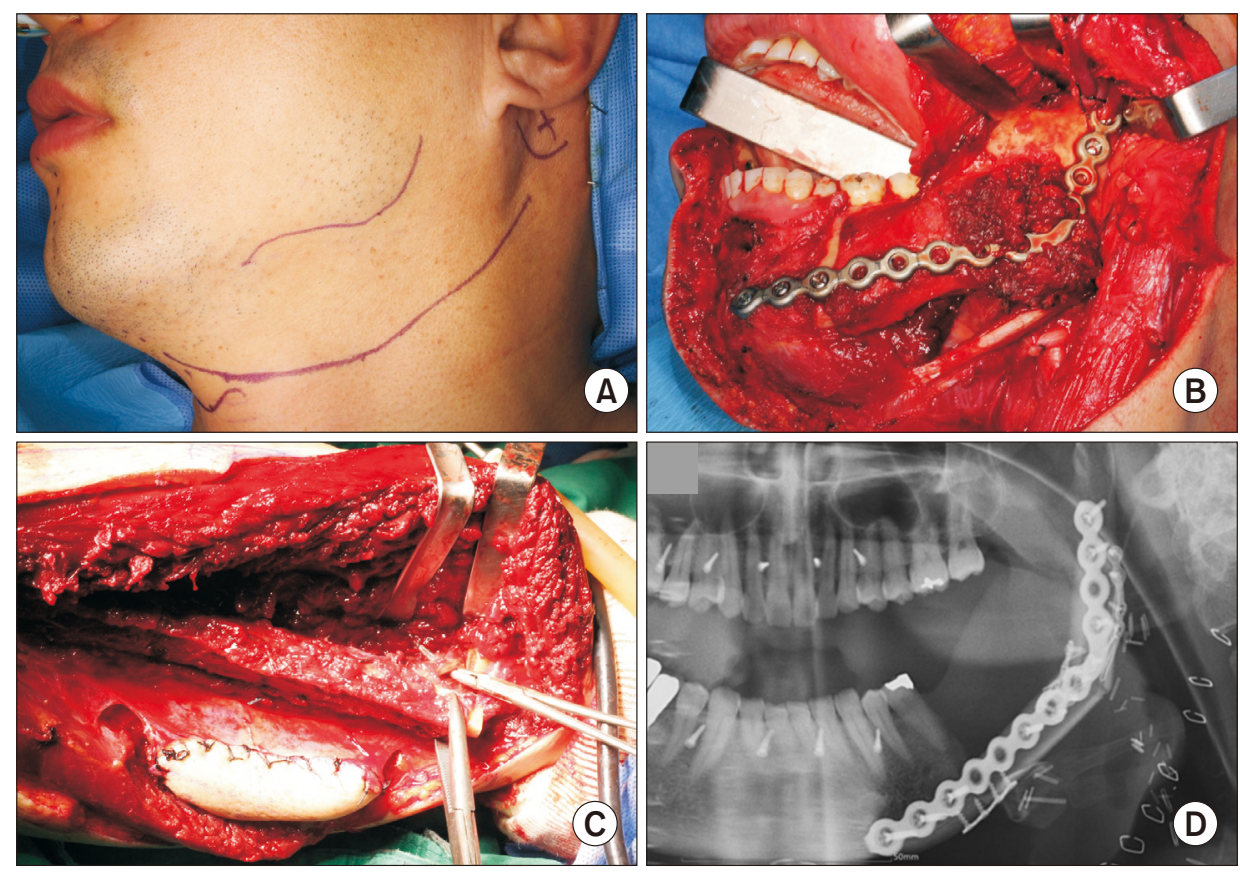

Fig. 9. A, B. Lesion on extraoral and intraoral site. C, D. Clinical (C) and radiographic (D) view of fibular free flap reconstruction.

Won-Bum Lee et al: Sequential treatment from mandibulectomy to reconstruction on mandibular oral cancer-Case review I: mandibular ramus and angle lesion of primary intraosseous squamous cell carcinoma. J Korean Assoc Oral Maxillofac Surg 2021

\section{Discussion}

PIOSCC is a rare malignant tumor that develops in the jaw. Diagnosis of PIOSCC can be difficult as it must be distinguished from other cancers, including malignant tumor metastases to the jaw and oral mucosal epithelium tumors that have invaded the bone. The etiology, prevalence, and incidence of PIOSCC have not been concluded'

PIOSCC is defined as an SCC that arises within the jaw. The WHO has proposed the term "primary intraosseous odontogenic carcinoma" to describe this type of $\mathrm{SCC}^{10}$. The WHO has subcategorized this lesion into three subtypes: a solid-type, a tumor arising from an odontogenic keratocyst, and a tumor associated with other epithelial odontogenic tumors ${ }^{7}$.

PIOSCC has a predilection for males (2:1 male-to-female ratio) and occurs often in the mandibular body and angle ${ }^{1}$. In this study, 36-year-old and 48-year-old males were affected, and the lesions involved the mandibular body, angle, and ramus areas.

Clinically, PIOSCC has some distinct symptoms according to type and size ${ }^{10}$. These symptoms are pain, swelling, lip numbness, and teeth mobility ${ }^{10}$. In this case study, the 36-year-old male patient reported pain in the lower right gin- 

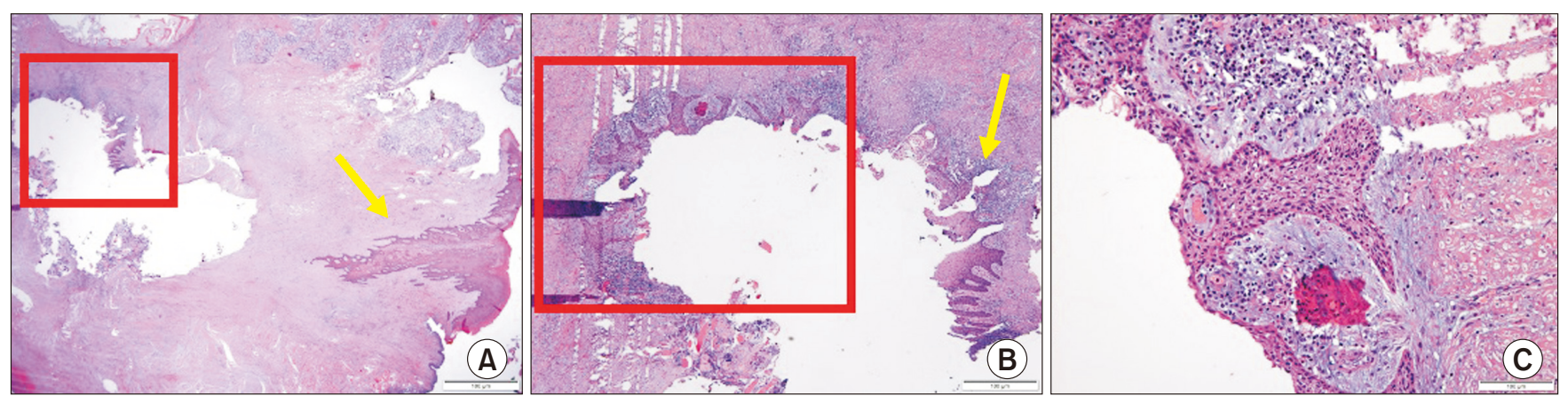

Fig. 10. Histological findings of Case 2 (H\&E staining). A. Hole view (×20) of cyst wall (square) and normal squamous epithelium (arrow). B. Magnification view $(\times 100)$ of the part of primary intraosseous squamous cell carcinoma (PIOSCC) (square) and normal squamous epithelium (arrow). C. Magnification view $(\times 200)$ of the part of PIOSCC. It shows a pattern of invasion to basal membrane and a small and thick nucleus which is different in size between other nuclei.

Won-Bum Lee et al: Sequential treatment from mandibulectomy to reconstruction on mandibular oral cancer-Case review I: mandibular ramus and angle lesion of primary intraosseous squamous cell carcinoma. J Korean Assoc Oral Maxillofac Surg 2021

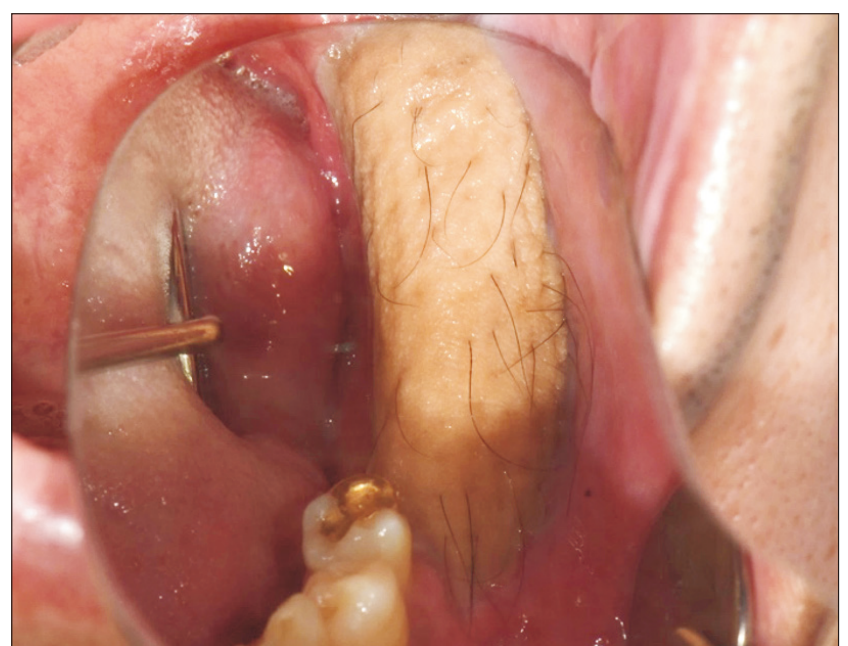

Fig. 11. The patient's intraoral view after 2 months postoperatively.

Won-Bum Lee et al: Sequential treatment from mandibulectomy to reconstruction on mandibular oral cancer - Case review I: mandibular ramus and angle lesion of primary intraosseous squamous cell carcinoma. J Korean Assoc Oral Maxillofac Surg 2021

giva of his molar region. The 48-year-old male patient experienced pain in the left mandibular gingiva of his molar area, with paresthesia of the left lower lip.

The hallmark radiographic features of PIOSCCs are similar to those of odontogenic tumors. Early stage PIOSCC can mimic odontogenic tumor or dental disorder, which could lead to misdiagnosis ${ }^{11}$. In this study, the author misdiagnosed the early stage PIOSCC lesion in the 48 -year-old male as osteomyelitis at the first visit. While the other patient did not have early stage PIOSCC, that patient's first dentist diagnosed the lesion as an odontogenic keratocyst. After resection and neck dissection, adjuvant radiotherapy and chemotherapy were not performed due to lack of neck metastasis.
Table 1. Summary of patient characteristics

\begin{tabular}{lcc}
\hline \multicolumn{1}{c}{ Variable } & Case 1 & Case 2 \\
\hline Age (yr) & 36 & 48 \\
Sex & Male & Male \\
Symptom & Pain & Pain \\
Location & Right mandible & Left mandible \\
Initial diagnosis & OKC & Osteomyelitis \\
Initial treatment & Cyst enucleation & Curettage \\
Final treatment & Wide excision & Wide excision \\
Subtype & Solid type & Arising from cyst \\
Stage & pT4aN0M0 & pT4aN1M0 \\
Adjuvant treatment & Negative & Positive \\
Follow-up period & 7 yr & 4 mo \\
\hline
\end{tabular}

(OKC: odontogenic keratocyst)

Won-Bum Lee et al: Sequential treatment from mandibulectomy to reconstruction on mandibular oral cancer - Case review I: mandibular ramus and angle lesion of primary intraosseous squamous cell carcinoma. J Korean Assoc Oral Maxillofac Surg 2021

Radiographically, in most cases, osteolytic bony changes are characterized by diffuse, ill-defined, and irregular margins ${ }^{11}$. In this study, the lesions showed similar features, including irregular osteolytic bony changes in both the 36-year-old and 48-year-old patients. MRI and PET-CT scanning modalities have advantages over other imaging techniques for anatomical assessment of head and neck cancers, especially with regard to mapping neck metastasis and primary tumor extent ${ }^{12}$. In our cases, the 48-year-old male patient had a left level-IIa neck metastasis visible on both MRI and PET-CT.

The prognosis of PIOSCC is generally not good, although well-differentiated SCC is reported to have a better progno$\mathrm{sis}^{6}$. Wenguang et al. ${ }^{13}$ reported estimated two-year and fiveyear overall survival rates of $68.9 \%$ and $38.8 \%$, respectively. de Morais et al. ${ }^{14}$ reported that PIOSCC has a poor prognosis, with high rates of mortality. Neck lymph node metastasis and histological grading have been suggested as prognostic indi- 
cators of these tumors ${ }^{6,15}$. Fortunately, the carcinomas were well-differentiated in both of our cases. In the 48-year-old male, a left level-IIa neck metastasis was confirmed. Concomitant chemotherapy and radiation therapy was performed, and the follow-up period was very short. Further follow-up will be needed to provide additional review of these cases.

\section{Conclusion}

The author presented two cases of PIOSCC.(Table 1) Case 1 (a 36-year-old male) had no lymph node metastasis and has shown no recurrence after seven years. Case 2 (a 48-year-old male) demonstrated a level-IIa lymph node metastasis and has shown no recurrence after six months. Both cases were misdiagnosed as other odontogenic diseases due to the type of PIOSCC lesion. The present cases highlight the importance of careful interpretation of radiographs.

\section{ORCID}

Won-Bum Lee, https://orcid.org/0000-0001-8383-8578

Dae-Seok Hwang, https://orcid.org/0000-0001-6899-1769

Uk-Kyu Kim, https://orcid.org/0000-0003-1251-7843

\section{Authors' Contributions}

W.B.L. participated in data collection and wrote the manuscript. D.S.H. contributed to conception and revision of the manuscript. U.K.K. provided with clinical data, participated in the study design and data analysis. All authors read and approved the final manuscript.

\section{Acknowledgements}

This study was supported by National Research Foundation of Korea and funded by the Korea government (No. 2019R1F1A1042528).

\section{Ethics Approval and Consent to Participate}

The study was approved by the Institutional Review Board of Pusan National University Dental Hospital (IRB No. PNUDH-2020-034). Informed consent was waived by the IRB.

\section{Consent for Publishing Photographs}

Written informed consent was obtained from the patients for publication of this article and accompanying images.

\section{Conflict of Interest}

No potential conflict of interest relevant to this article was reported.

\section{References}

1. Bodner L, Manor E, Shear M, van der Waal I. Primary intraosseous squamous cell carcinoma arising in an odontogenic cyst: a clinicopathologic analysis of 116 reported cases. J Oral Pathol Med 2011;40:733-8. https://doi.org/10.1111/j.1600-0714.2011.01058.x

2. Shear M. Primary intra-alveolar epidermoid carcinoma of the jaw. J Pathol 1969;97:645-51. https://doi.org/10.1002/path.1710970409

3. Chaisuparat R, Coletti D, Kolokythas A, Ord RA, Nikitakis NG. Primary intraosseous odontogenic carcinoma arising in an odontogenic cyst or de novo: a clinicopathologic study of six new cases. Oral Surg Oral Med Oral Pathol Oral Radiol Endod 2006;101:194200. https://doi.org/10.1016/j.tripleo.2005.03.037

4. McGowan RH. Primary intra-alveolar carcinoma. A difficult diagnosis. Br J Oral Surg 1980;18:259-65. https://doi.org/10.1016/0007$117 \mathrm{x}(80) 90071-2$

5. Thomas G, Pandey M, Mathew A, Abraham EK, Francis A, Somanathan T, et al. Primary intraosseous carcinoma of the jaw: pooled analysis of world literature and report of two new cases. Int J Oral Maxillofac Surg 2001;30:349-55. https://doi.org/10.1054/ ijom.2001.0069

6. Huang JW, Luo HY, Li Q, Li TJ. Primary intraosseous squamous cell carcinoma of the jaws. Clinicopathologic presentation and prognostic factors. Arch Pathol Lab Med 2009;133:1834-40. https://doi.org/10.1043/1543-2165-133.11.1834

7. Williams MD. Update from the 4th edition of the World Health Organization Classification of Head and Neck Tumours: mucosal melanomas. Head Neck Pathol 2017;11:110-7. https://doi. org/10.1007/s12105-017-0789-y

8. Sharma M, Wakure A, Thankappan K, Mathew J, Jairaj D, Dudipala RR, et al. Anatomic basis for an algorithmic approach for free fibula flap donor side selection in composite oromandibular defects. Indian J Plast Surg 2015;48:43-7. https://doi. org/10.4103/0970-0358.155268

9. Thakur A, Tupkari JV, Joy T, Gogri AA. Primary intraosseous squamous cell carcinoma - a rare odontogenic malignancy. J Oral Maxillofac Pathol 2017;21:320. https://doi.org/10.4103/jomfp. JOMFP_25_16

10. Suei Y, Taguchi A, Tanimoto K. Recommendation of modified classification for odontogenic carcinomas. Med Hypotheses 2004;62:382-6. https://doi.org/10.1016/j.mehy.2003.11.010

11. Elzay RP. Primary intraosseous carcinoma of the jaws. Review and update of odontogenic carcinomas. Oral Surg Oral Med Oral Pathol 1982;54:299-303. https://doi.org/10.1016/0030-4220(82)90099-8

12. Dai YL, King AD. State of the art MRI in head and neck cancer. Clin Radiol 2018;73:45-59. https://doi.org/10.1016/ j.crad.2017.05.020

13. Wenguang X, Hao S, Xiaofeng Q, Zhiyong W, Yufeng W, Qingang $\mathrm{H}$, et al. Prognostic factors of primary intraosseous squamous cell carcinoma (PIOSCC): a retrospective review. PLoS One 2016;11:e153646. https://doi.org/10.1371/journal.pone.0153646 
14. de Morais EF, Carlan LM, de Farias Morais HG, Pinheiro JC, Martins HDD, Barboza CAG, et al. Primary intraosseous squamous cell carcinoma involving the jaw bones: a systematic review and update. Head Neck Pathol 2020. https://doi.org/10.1007/s12105020-01234-z [Epub ahead of print]

15. Dimitrakopoulos I, Psomaderis K, Asimaki A, Papaemanouel S, Karakasis D. Primary de novo intraosseous carcinoma: report of two cases. J Oral Maxillofac Surg 2005;63:1227-30. https://doi. org/10.1016/j.joms.2005.04.009
How to cite this article: Lee WB, Hwang DS, Kim UK. Sequential treatment from mandibulectomy to reconstruction on mandibular oral cancer - Case review I: mandibular ramus and angle lesion of primary intraosseous squamous cell carcinoma. J Korean Assoc Oral Maxillofac Surg 2021;47:120-127. https://doi.org/10.5125/ jkaoms.2021.47.2.120 